ISSN 1561-8323 (Print)

ISSN 2524-2431 (Online)

УДК 617.713-007.17-002

https://doi.org/10.29235/1561-8323-2021-65-3-345-354
Поступило в редакцию 15.03.2021

Received 15.03.2021

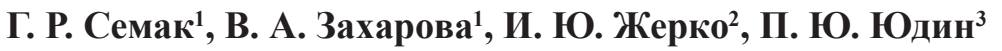 \\ ${ }^{1}$ Белорусский государственный медицинский университет, Минск, Республика Беларусь \\ 2Республиканский научно-практический центр онкологии и медичинской радиологии \\ им. Н. Н. Александрова, Лесной, Республика Беларусь \\ ${ }^{3}$ Третья городская клиническая больнища им Е. В. Клумова, Минск, Республика Беларусь

\section{ЭКСПРЕССИЯ ЛЮМИКАНА ПРИ ХРОНИЧЕСКИХ ДИСТРОФИЧЕСКИХ ЗАБОЛЕВАНИЯХ РОГОВИЦЫ}

\author{
(Представлено членом-корреспондентом Н. С. Сердюченко)
}

\begin{abstract}
Аннотация. Установлены характер экспрессии люмикана в эксплантах роговиц пациентов с хроническими дистрофическими заболеваниями роговицы, а также изменения его экспрессии на фоне применения инъекционной формы 1 \%-ного натрия гиалуроната. В проспективное исследование были включены 37 пациентов с хроническими дистрофическими заболеваниями роговицы: кератопатиями в исходе кератитов (20 случаев) и эндотелиально-эпителиальной дистрофией (17 случаев). Пациенты были разделены на 2 группы. Первая в предоперационном периоде получала курс инъекций 1 \%-ного низкомолекулярного натрия гиалуроната, вторая не получала дополнительного лечения. Всем включенным в исследование пациентам была выполнена сквозная кератопластика. Выполнено иммуногистохимическое исследование роговичных эксплантов с использованием первичных моноклональных антител к люмикану с последующей морфометрической оценкой препаратов. Рассчитывались доля пикселей с высокой и умеренной интенсивностью и индекс интенсивности экспрессии в иммунопозитивных участках. В группе пациентов с агрессивными кератитами интенсивность экспрессии люмикана как в эпителии, так и строме роговицы была статистически значимо выше по сравнению с группой контроля и снижалась на фоне применения 1 \%-ного низкомолекулярного натрия гиалуроната. При формировании бельма экспрессия люмикана как в эпителии, так и в строме роговицы была сопоставима с таковой в группе контроля с более высокими параметрами эпителиальной экспрессии на фоне применения натрия гиалуроната. В группах эндотелиально-эпителиальных дистрофий отмечалось повышение интенсивности экспрессии на фоне применения натрия гиалуроната. Отмеченное повышение эпителиальной экспрессии люмикана на фоне выраженной альтерации сопровождается постепенным ее снижением по мере завершения регенерации. Важным фактором является его нормальное содержание в строме роговицы, поскольку как резкое повышение, так и низкие параметры экспрессии сопровождаются снижением прозрачности роговицы.

Ключевые слова: кератит, эндотелиально-эпителиальная дистрофия, люмикан, натрия гиалуронат, иммуногистохимия

Для цитирования. Экспрессия люмикана при хронических дистрофических заболеваниях роговицы / Г. Р. Семак [и др.] // Докл. Нац. акад. наук Беларуси. - 2021. - Т. 65, № 3. - С. 345-354. https://doi.org/10.29235/1561-8323-202165-3-345-354
\end{abstract}

Galina R. Semak ${ }^{1}$, Viktoria A. Zakharava ${ }^{1}$, Iryna Yu. Zherka², Pavel Yu. Yudin ${ }^{3}$

${ }^{1}$ Belarusian State Medical University, Minsk, Republic of Belarus

${ }^{2}$ N. N. Alexandrov National Cancer Centre of Belarus, Lesnoy, Republic of Belarus

${ }^{3} 3$ rd City Clinical Hospital named after E. V. Klumov, Minsk, Republic of Belarus

\title{
LUMICAN EXPRESSION IN CHRONIC DEGENERATIVE CORNEA DISEASES
}

\author{
(Communicated by Corresponding Member Nikolay S. Serduchenko)
}

Abstract. The pattern of lumican expression in corneal explants of patients with chronic dystrophic cornea diseases and the changes in its expression after $1 \%$ sodium hyaluronate expression are established. The prospective study included 37 patients with chronic dystrophic diseases of the cornea: keratopathies in the outcome of keratitis (20 cases) and endothelial-epithelial dystrophy (17 cases). The patients were divided into 2 groups. The first group in the preoperative period received the injections of $1 \%$ low molecular weight sodium hyaluronate, the second group did not receive additional treatment. All patients included in the study underwent penetrating keratoplasty. The immunohistochemical study of corneal explants was performed using primary monoclonal antibodies to lumican with subsequent morphometric evaluation of the preparations. The proportion of pixels with high and moderate intensity and the index of expression intensity in immunopositive regions 
were calculated. In the group of patients with aggressive keratitis, the intensity of lumican expression both in the epithelium and in the corneal stroma was statistically significantly higher than in the control group and decreased with the use of $1 \%$ low molecular weight sodium hyaluronate. After the leukoma formation, the expression of lumican both in the epithelium and in the corneal stroma was comparable to that in the control group with higher parameters of epithelial expression after sodium hyaluronate administration. In the groups of endothelial-epithelial dystrophy, an increase in the intensity of expression was noted after sodium hyaluronate injections. The noted increase in the epithelial expression of lumican against the background of pronounced alteration is accompanied by its gradual decrease as the regeneration is completed. An important factor is its normal content in the corneal stroma, since both a sharp increase and low expression parameters are accompanied by a decrease in corneal transparency.

Keywords: keratitis, endothelial-epithelial dystrophy, lumikan, sodium hyaluronate, immunohistochemistry

For citation. Semak G. R., Zakharava V. A., Zherka I. Yu., Yudin P. Yu. Lumican expression in chronic degenerative cornea diseases. Doklady Natsional'noi akademii nauk Belarusi = Doklady of the National Academy of Sciences of Belarus, 2021, vol. 65, no. 3, pp. 345-354 (in Russian). https://doi.org/10.29235/1561-8323-2021-65-3-345-354

Введение. Хронические дистрофические заболевания роговицы (ХДЗР) - группа заболеваний роговицы, сопровождающихся снижением ее прозрачности. Чаще всего патологические процессы затрагивают строму или эпителий роговицы. Формирование помутнений в оптической зоне ведет к значительному ухудшению зрения пациента, вплоть до слепоты, что в свою очередь, снижает качество жизни, а в ряде случаев приводит к инвалидизации.

Изучение патогенеза и разработка новых методов лечения ХДЗР являются актуальными проблемами современной офтальмологии. Ранее нами была проанализирована роль CD44, MMP9, TGFß1 в патогенезе кератопатий и процессах регенерации в тканях роговицы на фоне применения $1 \%$-ного низкомолекулярного натрия гиалуроната [1;2].

Гиалуроновая кислота массой 500-700 кДа является биологически активной молекулой. Сообщается, что она способна индуцировать дифференцировку мезенхимальных клеток (хондроцитов, кератиноцитов, фибробластов, эндотелиоцитов), опосредуя ответ на повреждения [3; 4], ускорять заживление ран путем индукции экспрессии CD44, RHAMM и накопления коллагена третьего типа [5]. Также на культуре фибробластов синовиальной оболочки было показано, что экзогенная гиалуроновая кислота разной молекулярной массы способна индуцировать синтез эндогенной гиалуроновой кислоты [6]. В исследованиях нами ранее была показана клиническая эффективность $1 \%$-ного низкомолекулярного натрия гиалуроната в лечении ХДЗР. На фоне субконъюнктивального введения препарата увеличивалась прозрачность роговицы, а также уменьшались проявления болезни сухого глаза, улучшалось качество слезной пленки $[1 ; 2]$.

Люмикан является ключевым компонентом внеклеточного матрикса роговицы и обеспечивает прозрачность стромы последней. В исследованиях на животных показана его важная роль при глаукоме, миопии высокой степени, острых воспалительных заболеваниях и травмах роговицы [7].

Цель - установить характер экспрессии люмикана в эксплантах роговиц пациентов с хроническими дистрофическими заболеваниями роговицы, а также изменения его экспрессии на фоне применения инъекционной формы 1 \%-ного натрия гиалуроната.

Материалы и методы исследования. Исследование выполнено на базе кафедры глазных болезней и патологической анатомии учреждения образования «Белорусский государственный медицинский университет».

В проспективное исследование были включены 37 пациентов с хроническими дистрофическими заболеваниями роговицы (ХДЗР): кератопатиями в исходе кератитов (20 случаев) и эндотелиально-эпителиальной дистрофией (ЭЭД) (17 случаев), обратившихся в 2017-2019 гг. для обследования и последующего лечения в УЗ «3-я городская клиническая больница им. Е. В. Клумова».

Клинико-лабораторное обследование включало: визометрию, биомикроскопию, тонометрию, тест Ширмера I, LIPCOF-тест, определение времени разрыва слезной пленки, оптическую когерентную томографию переднего отрезка глазного яблока. Пациенты с признаками острой инфекции глазной поверхности из исследования исключались.

Пациенты были разделены на 2 группы. Первая группа в предоперационном периоде получала курс инъекций 1 \%-ного низкомолекулярного натрия гиалуроната (3 еженедельные инъекции) $\left(Г K^{+}\right)$, вторая группа не получала дополнительного лечения $\left(Г К^{-}\right)$. Контроль состояния глазной поверхности (биомикроскопия) осуществлялся перед каждой инъекцией. Исследуемые группы с учетом этиологии ХДЗР были сопоставимы по основным клинико-демографическим критериям. 
Всем включенным в исследование пациентам была выполнена сквозная кератопластика по показаниям. В качестве контроля использовались экспланты роговиц нормального строения (табл. 1)

Т а б л и ц а 1. Структура материала для анализа морфологических и иммуногистохимических признаков

$\mathrm{T}$ a $\mathrm{b} 1 \mathrm{e}$. Structure of the material for analysis of morphological and immonohistochemical symptoms

\begin{tabular}{|c|c|c|}
\hline $\begin{array}{l}\text { Нозологическая форма } \\
\text { Nosological form }\end{array}$ & $\begin{array}{l}\text { Число случаев } \\
\text { Number of cases }\end{array}$ & $\begin{array}{c}\text { Число полей зрения }(\times 40) \\
\text { Number of fields of view }(\times 40)\end{array}$ \\
\hline Контроль & 3 & 18 \\
\hline Кератиты («+» гиалуроновая кислота) & 10 & 60 \\
\hline Кератиты («-» гиалуроновая кислота) & 10 & 60 \\
\hline $\begin{array}{l}\text { Эндотелиально-эпителиальная дистрофия («+» гиалуро- } \\
\text { новая кислота) }\end{array}$ & 9 & 54 \\
\hline $\begin{array}{l}\text { Эндотелиально-эпителиальная дистрофия («-» гиалуро- } \\
\text { новая кислота) }\end{array}$ & 8 & 48 \\
\hline Всего & 40 & 240 \\
\hline
\end{tabular}

С целью анализа характера экспрессии люмикана выполнено иммуногистохимическое (ИГХ) исследование с использованием первичных моноклональных антител к люмикану. В качестве визуализирующей системы использовали комплекс вторичных антител EnVision фирмы «DAKO», в качестве хромогена - диаминобензидин (ДАБ). Позитивный контроль - ткани и органы, рекомендованные производителем, негативный - исключение первичного антитела.

Для морфометрического анализа выполняли сканирование препаратов с применением цифрового слайд-сканера MoticEasyScan с последующим программным анализом эпителиальной и стромальной экспрессии маркера в материале ткани роговицы с использованием AperioImageScope v12.4.0.5043. Рассчитывались следующие параметры: доля пикселей с высокой и умеренной интенсивностью $((\mathrm{Nsr}+\mathrm{p})$ - отношение числа позитивных пикселей с высокой и умеренной интенсивностью к общему числу позитивных и негативных пикселей $\times 100 \%$ ); индекс интенсивности экспрессии в иммунопозитивных участках (index - отношение суммы интенсивностей пикселей с высокой, средней, низкой интенсивностью к числу позитивных пикселей).

Статистический анализ данных проводился с использованием программного обеспечения Statistica 10.0. Анализ проводился отдельно для каждой из нозологий. Полученные результаты обработаны статистически с вычислением медианы (Ме), межквартильного размаха (МКР $25 \%$ и $75 \%$ процентили) и $95 \%$-ного доверительного интервала (ДИ), максимального и минимального значения. Для оценки характера распределения полученных данных использовался критерий Шапиро-Уилка $(W)$. Уровень статистической значимости - 0,05. Сравнение независимых выборок по количественным признакам проводилось с использованием дисперсионного анализа непараметрических данных ANOVA и определением критериев Краскела-Уоллиса ( $H$-критерий) для трех и более выборок и Манна-Уитни ( $U$-критерий) с целью парного сравнения выборок.

Результаты и их обсуждение. Во всех группах в эксплантах роговиц выявлялась цитоплазматическая экспрессия люмикана в эпителии с преобладанием окрашивания базальных кератиноцитов, кератоцитах и соединительнотканных волокнах стромы, клетках воспалительного инфильтрата и эндотелии с отсутствием или фоновым окрашиванием боуменовой и десцеметовой мембран (рис. 1).

Иммуноморфологическая характеристика экспрессии молекулярных маркеров в группе с ХДЗР в исходе кератитов. В группе пациентов с ХДЗР в исходе кератита (К) экспрессия люмикана в эпителии роговицы была сопоставима с таковой в группе контроля, а в строме статистически значимо превышала контрольные параметры с преобладанием наиболее выраженной стромальной экспрессии в очагах воспалительной инфильтрации (табл. 2, рис. 2). 


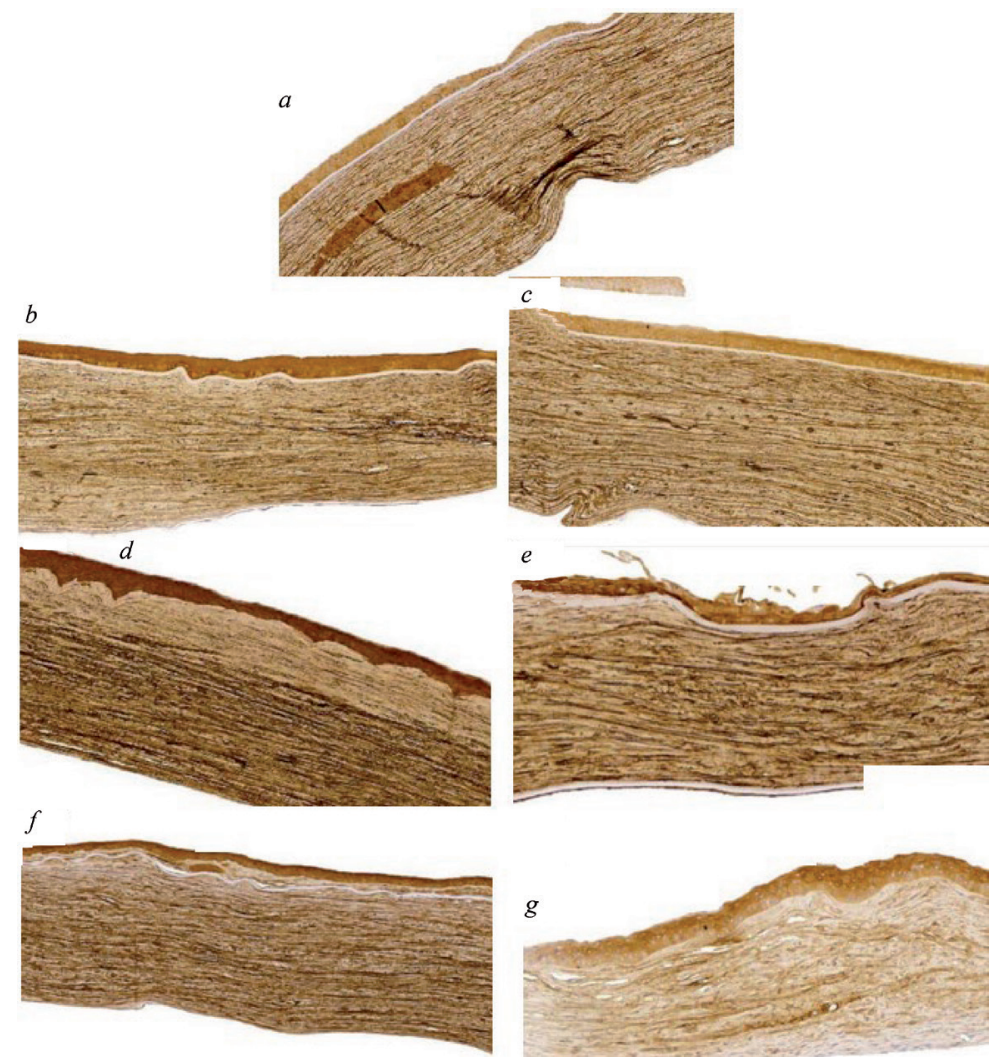

Рис. 1. Экспрессия люмикана в тканях эксплантов роговиц в группе контроля $(a)$, в группе пациентов с кератитами $\left(b-\Gamma K^{-}, c-\Gamma K^{+}\right)$, в группе пациентов с наследственными ЭЭД $\left(d-\Gamma K^{-}, e-\Gamma K^{+}\right)$, в группе пациентов с приобретенной

ЭЭД $\left(f-\Gamma K^{-}, g-\Gamma K^{+}\right)$. Иммуногистохимический метод. Хромоген - диаминобензидин. Контрокрашивание гематоксилином Майера. Объектив $\times 40$

Fig. 1. Lumican expression in the corneal explant tissues in the control group $(a)$, in the group of keratitis patients $\left(b-\Gamma K^{-}, c-\Gamma K^{+}\right)$, in the group of patients with chronic dystrophic diseases of the cornea $\left(d-\Gamma K^{-}, e-\Gamma K^{+}\right)$, in the group of patients with acquired endothelial-epithelial dystrophy $\left(f-\Gamma K^{-}, g-\Gamma K^{+}\right)$. Immunohistochemical method. Chromogene diaminobenzidine. Counter-stopping - Mayer's hematoxylin. Object-glass $\times 40$

Т а б л и ц а 2. Дисперсионный анализ площади выраженной и умеренной экспрессии и индекса интенсивности экспрессии люмикана в тканях роговицы при ХДЗР в исходе кератитов

$\mathrm{T}$ a $\mathrm{b}$ l e 2. Dispersion analysis of the pronounced and moderate expression area and the index of lumican expression intensity in corneal tissues in chronic dystrophic diseases of the cornea in the keratitis outcome

\begin{tabular}{|c|c|c|c|c|c|c|}
\hline \multirow[t]{2}{*}{$\begin{array}{l}\text { Группа } \\
\text { Group }\end{array}$} & \multirow[t]{2}{*}{$\begin{array}{c}\text { Контроль } \\
\text { Control }\end{array}$} & \multirow{2}{*}{$\begin{array}{c}\text { ХДЗР в исходе } \\
\text { кератитов } \\
\text { Chronic dystrophic } \\
\text { diseases of the } \\
\text { cornea in the } \\
\text { keratitis outcome } \\
\text { ГК }^{-}\end{array}$} & \multicolumn{2}{|c|}{$\begin{array}{c}\text { ХДЗР в исходе кератита } \\
\text { на фоне ожоговой болезни } \\
\text { Chronic dystrophic diseases of the cornea } \\
\text { in the keratitis outcome on the background } \\
\text { of burn disease }\end{array}$} & \multicolumn{2}{|c|}{$\begin{array}{l}\text { ХДЗР в исходе кератитов } \\
\text { с формированием бельма } \\
\text { Chronic dystrophic diseases of the cornea } \\
\text { in the keratitis outcome with the formation } \\
\text { of a wall-eye }\end{array}$} \\
\hline & & & $\Gamma \mathrm{K}^{-}$ & $\Gamma \mathrm{K}^{+}$ & $\Gamma \mathrm{K}^{-}$ & $\Gamma \mathrm{K}^{+}$ \\
\hline \multicolumn{7}{|c|}{ Доля пикселей с умеренной и выраженной экспрессией люмикана в эпителии, \% } \\
\hline $\mathrm{Me}[\mathrm{MKP}]$ & $\begin{array}{c}95,2 \\
{[79,1 ; 97,8]}\end{array}$ & $\begin{array}{c}90,2 \\
{[82,7 ; 94,1]}\end{array}$ & $\begin{array}{c}99,1 \\
{[98,4 ; 99,2]}\end{array}$ & $\begin{array}{c}95,1 \\
{[94,3 ; 96,2]}\end{array}$ & $\begin{array}{c}91,0 \\
{[69,9 ; 94,7]}\end{array}$ & $\begin{array}{c}97,3 \\
{[96,6 ; 98,1]}\end{array}$ \\
\hline Контроль & & $p=0,51$ & $p=0,004^{*}$ & $p=0,896$ & $p=0,19$ & $p=0,117$ \\
\hline$\Gamma \mathrm{K}^{-} / \Gamma \mathrm{K}^{+}$ & & & \multicolumn{2}{|c|}{$p=0,019 *$} & \multicolumn{2}{|c|}{$p<0,001^{*}$} \\
\hline \multicolumn{7}{|c|}{ Индекс интенсивности экспрессии люмикана в эпителии } \\
\hline Мe [MКР] & $\begin{array}{c}109 \\
{[84 ; 125]}\end{array}$ & $\begin{array}{c}114 \\
{[85 ; 124]}\end{array}$ & $\begin{array}{c}49 \\
{[45 ; 51]}\end{array}$ & $\begin{array}{c}101 \\
{[98 ; 105]}\end{array}$ & $\begin{array}{c}118 \\
{[106 ; 142]}\end{array}$ & $\begin{array}{c}78 \\
{[71 ; 86]} \\
\end{array}$ \\
\hline Контроль & & $p=0,93$ & $p=0,001^{*}$ & $p=0,602$ & $p=0,17$ & $p=0,021^{*}$ \\
\hline$\Gamma \mathrm{K}^{-} / \Gamma \mathrm{K}^{+}$ & & & \multicolumn{2}{|c|}{$p=0,011^{*}$} & \multicolumn{2}{|c|}{$p<0,001^{*}$} \\
\hline
\end{tabular}


Окончание табл. 2

\begin{tabular}{|c|c|c|c|c|c|c|}
\hline \multirow[t]{2}{*}{$\begin{array}{l}\text { Группа } \\
\text { Group }\end{array}$} & \multirow[t]{2}{*}{$\begin{array}{l}\text { Контроль } \\
\text { Control }\end{array}$} & \multirow{2}{*}{$\begin{array}{c}\text { ХДЗР в исходе } \\
\text { кератитов } \\
\text { Chronic dystrophic } \\
\text { diseases of the } \\
\text { cornea in the } \\
\text { keratitis outcome } \\
\text { ГК }^{-} \\
\end{array}$} & \multicolumn{2}{|c|}{$\begin{array}{c}\text { ХДЗР в исходе кератита } \\
\text { на фоне ожоговой болезни } \\
\text { Chronic dystrophic diseases of the cornea } \\
\text { in the keratitis outcome on the background } \\
\text { of burn disease }\end{array}$} & \multicolumn{2}{|c|}{$\begin{array}{c}\text { ХДЗР в исходе кератитов } \\
\text { с формированием бельма } \\
\text { Chronic dystrophic diseases of the cornea } \\
\text { in the keratitis outcome with the formatior } \\
\text { of a wall-eye }\end{array}$} \\
\hline & & & ГК & $\Gamma \mathrm{K}^{+}$ & $\Gamma \kappa^{-}$ & $\Gamma \mathrm{K}^{+}$ \\
\hline \multicolumn{7}{|c|}{ Доля пикселей с умеренной и выраженной экспрессией люмикана в строме, \% } \\
\hline $\mathrm{Me}[\mathrm{MKP}]$ & $\begin{array}{c}86,0 \\
{[83,3 ; 89,3]}\end{array}$ & $\begin{array}{c}98,1 \\
{[97,9 ; 98,8]} \\
\end{array}$ & $\begin{array}{c}94,2 \\
{[92,9 ; 94,6]}\end{array}$ & $\begin{array}{c}72,5 \\
{[70,8 ; 78,3]} \\
\end{array}$ & $\begin{array}{c}81,5 \\
{[71,3 ; 92,1]} \\
\end{array}$ & $\begin{array}{c}83,9 \\
{[79,3 ; 86,6]}\end{array}$ \\
\hline Контроль & & $p=0,001^{*}$ & $p=0,049^{*}$ & $p=0,001^{*}$ & $p=0,18$ & $p=0,155$ \\
\hline$\Gamma \mathrm{K}^{-} / \Gamma \mathrm{K}^{+}$ & & & \multicolumn{2}{|c|}{$p=0,004^{*}$} & \multicolumn{2}{|c|}{$p=0,983$} \\
\hline \multicolumn{7}{|c|}{ Индекс интенсивности экспрессии люмикана в строме } \\
\hline $\mathrm{Me}[\mathrm{MKP}]$ & $\begin{array}{c}111 \\
{[10 ; 118]}\end{array}$ & $\begin{array}{c}89 \\
{[82 ; 96]} \\
\end{array}$ & $\begin{array}{c}93 \\
{[89 ; 97]} \\
\end{array}$ & $\begin{array}{c}139 \\
{[134 ; 145]} \\
\end{array}$ & $\begin{array}{c}118 \\
{[98 ; 134]}\end{array}$ & $\begin{array}{c}120 \\
{[112 ; 123]} \\
\end{array}$ \\
\hline Контроль & & $p=0,004^{*}$ & $p=0,011^{*}$ & $p<0,001^{*}$ & $p=0,33$ & $p=0,047^{*}$ \\
\hline$\Gamma \mathrm{K}^{-} / \Gamma \mathrm{K}^{+}$ & & & \multicolumn{2}{|c|}{$p=0,004 *$} & \multicolumn{2}{|c|}{$p=0,693$} \\
\hline
\end{tabular}

Пр и м е ч ан и е. *- -различия достоверны при $p<0,05$.

Note. ${ }^{*}$ - differences are significant at $p<0.05$.
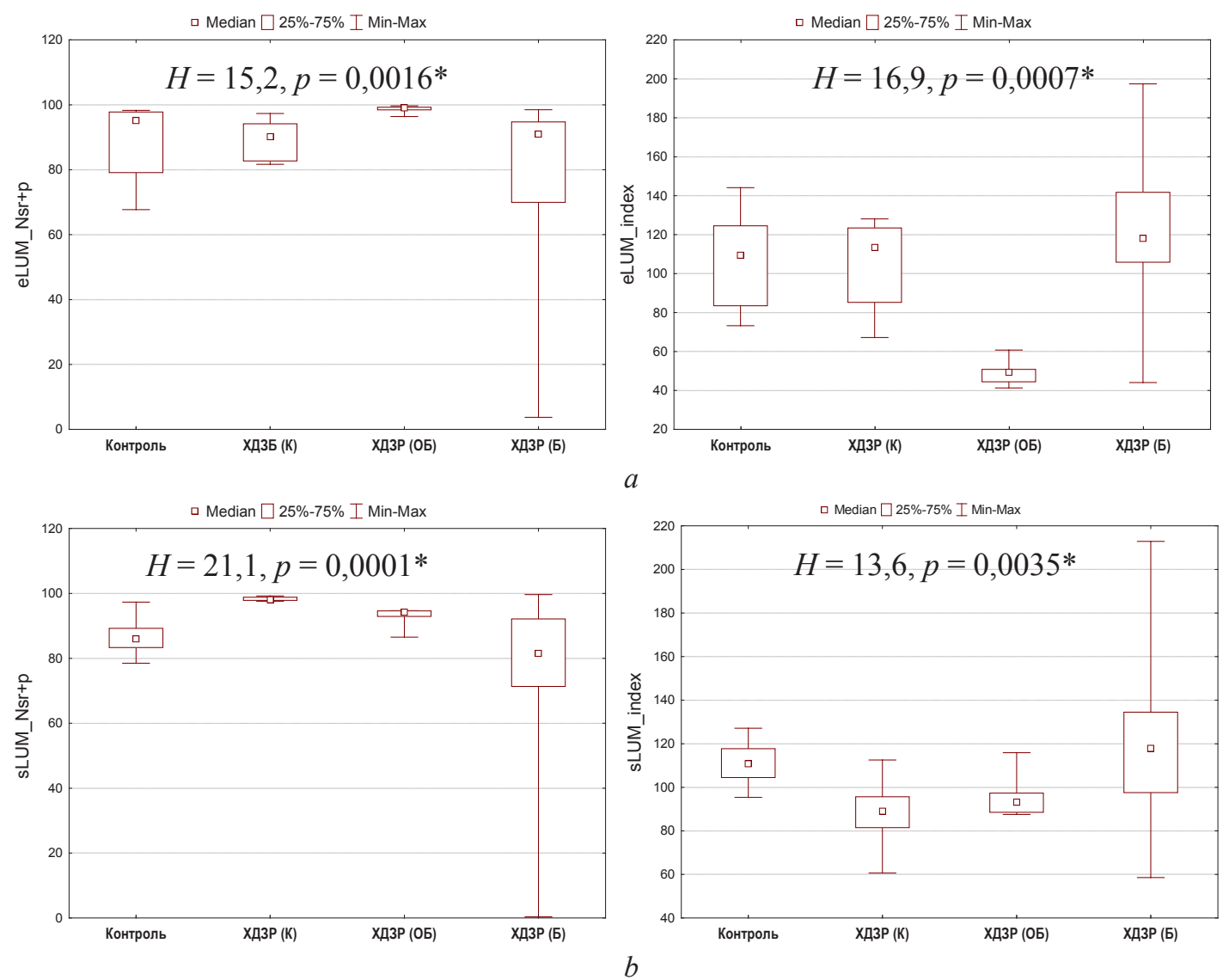

Рис. 2. Характер экспрессии люмикана в эпителии $(a)$ и строме $(b)$ эксплантов роговиц пациентов с ХДЗР в исходе кератитов

Fig. 2. Lumican expression nature in epithelium (a) and stroma (b) of corneal explants of patients with chronic dystrophic diseases of the cornea in the keratitis outcome

В группе пациентов с ХДЗР в исходе кератита на фоне ожоговой болезни (ОБ), интенсивность ИГХ реакции и площадь умеренной и выраженной экспрессии люмикана как в эпителии, так и в строме роговицы была статистически значимо выше по сравнению с группой контроля с преобладанием наиболее выраженной экспрессии в зоне альтеративных изменений и фокусов 
регенерации эпителия и воспалительной инфильтрации в строме. На фоне применения 1 \%-ного низкомолекулярного натрия гиалуроната по сравнению со стандартной терапией в данной группе статистически значимо меньшие значения площади и интенсивности стромальной экспрессии маркера и сопоставимые с контрольными значениями параметры эпителиальной экспрессии люмикана.

В группе же пациентов с ХДЗР в исходе кератитов с формированием бельма (Б) экспрессия люмикана как в эпителии, так и строме роговицы была сопоставима с таковой в группе контроля со значимо более высокими параметрами интенсивности эпителиальной и более низкими параметрами интенсивности стромальной экспрессии люмикана на фоне применения 1 \%-ного низкомолекулярного натрия гиалуроната по сравнению со стандартной терапией.

Иммуноморфологическая характеристика экспрессии молекулярных маркеров в группе наследственных ЭЭД. В группе наследственных эндотелиально-эпителиальных дистрофий не наблюдалось значимых различий параметров эпителиальной экспрессии люмикана по сравнению с группой контроля и отмечались более высокие значения интенсивности эпителиальной экспрессии маркера на фоне применения 1 \%-ного натрия гиалуроната. Одновременно, доля пикселей с умеренной и выраженной стромальной экспрессией люмикана и интенсивность ИГХ реакции в группе пациентов с наследственными формами эндотелиально-эпителиальных дистрофий были статистически значимо ниже по сравнению с группой контроля и возрастали до нормальных значений и выше на фоне применения 1 \%-ного низкомолекулярного натрия гиалуроната (табл. 3, рис. 3).

Т а б л и ц а 3. Дисперсионный анализ характера экспрессии люмикана в тканях роговицы при ЭЭД

$\mathrm{T}$ a b 1 e 3. Dispersion analysis of the nature of the lumican expression in corneal tissues at endothelial-epithelial dystrophy

\begin{tabular}{|c|c|c|c|c|c|}
\hline \multirow{2}{*}{$\begin{array}{l}\text { Группа } \\
\text { Group }\end{array}$} & \multirow{2}{*}{$\begin{array}{l}\text { Контроль } \\
\text { Control }\end{array}$} & \multicolumn{2}{|c|}{$\begin{array}{c}\text { ЭЭД наследственные } \\
\text { Hereditary endothelial-epithelial dystrophy }\end{array}$} & \multicolumn{2}{|c|}{$\begin{array}{c}\text { ЭЭД приобретенные } \\
\text { Acquired endothelial-epithelial dystrophy }\end{array}$} \\
\hline & & $\begin{array}{r}K^{-} \\
\end{array}$ & $\Gamma \mathrm{K}^{+}$ & $\Gamma^{-}$ & $\Gamma \mathrm{K}^{+}$ \\
\hline \multicolumn{6}{|c|}{ Доля пикселей с умеренной и выраженной экспрессией люмикана в эпителии, \% } \\
\hline Мe $[\mathrm{MKP}]$ & $\begin{array}{c}95,2 \\
{[79,1 ; 97,8]}\end{array}$ & $\begin{array}{c}93,4 \\
{[88,4 ; 98,1]}\end{array}$ & $\begin{array}{c}97,9 \\
{[96,7 ; 98,5]}\end{array}$ & $\begin{array}{c}92,1 \\
{[87,2 ; 97,8]}\end{array}$ & $\begin{array}{c}92,8 \\
{[92,1 ; 96,8]}\end{array}$ \\
\hline \multirow[t]{2}{*}{ Контроль } & & $p=0,34$ & $p=0,21$ & $p=0,70$ & $p=0,95$ \\
\hline & & \multicolumn{2}{|c|}{$p=0,37$} & \multicolumn{2}{|c|}{$p=0,95$} \\
\hline \multicolumn{6}{|c|}{ Индекс интенсивности экспрессии люмикана в эпителии } \\
\hline Мe [MКР] & $\begin{array}{c}109 \\
{[84 ; 125]}\end{array}$ & $\begin{array}{c}105 \\
{[96 ; 112]}\end{array}$ & $\begin{array}{c}67 \\
{[61 ; 74]}\end{array}$ & $\begin{array}{c}112 \\
{[93 ; 141]}\end{array}$ & $\begin{array}{c}87 \\
{[82 ; 97]}\end{array}$ \\
\hline \multirow[t]{2}{*}{ Контроль } & & $p=0,59$ & $p=0,30$ & $p=0,32$ & $p=0,28$ \\
\hline & & \multicolumn{2}{|c|}{$p=0,001^{*}$} & \multicolumn{2}{|c|}{$p=0,047^{*}$} \\
\hline \multicolumn{6}{|c|}{ Доля пикселей с умеренной и выраженной экспрессией люмикана в строме, \% } \\
\hline $\mathrm{Me}[\mathrm{MKP}]$ & $\begin{array}{c}86,0 \\
{[83,3 ; 89,3]}\end{array}$ & $\begin{array}{c}81,5 \\
{[10,9 ; 86,7]}\end{array}$ & $\begin{array}{c}90,0 \\
{[88,2 ; 91,0]}\end{array}$ & $\begin{array}{c}80,9 \\
{[66,8 ; 86,6]}\end{array}$ & $\begin{array}{c}82,6 \\
{[82,2 ; 83,6]}\end{array}$ \\
\hline \multirow[t]{2}{*}{ Контроль } & & $p=0,048^{*}$ & $p=0,003^{*}$ & $p=0,010^{*}$ & $p=0,058$ \\
\hline & & \multicolumn{2}{|c|}{$p=0,06$} & \multicolumn{2}{|c|}{$p=0,78$} \\
\hline \multicolumn{6}{|c|}{ Индекс интенсивности экспрессии люмикана в строме } \\
\hline Me $[\mathrm{MKP}]$ & $\begin{array}{c}111 \\
{[10 ; 118]}\end{array}$ & $\begin{array}{c}125 \\
{[115 ; 186]}\end{array}$ & $\begin{array}{c}95 \\
{[94 ; 100]}\end{array}$ & $\begin{array}{c}124 \\
{[109 ; 137]}\end{array}$ & $\begin{array}{c}115 \\
{[115 ; 117]}\end{array}$ \\
\hline \multirow[t]{2}{*}{ Контроль } & & $p=0,003^{*}$ & $p=0,033^{*}$ & $p=0,058$ & $p=0,29$ \\
\hline & & \multicolumn{2}{|c|}{$p=0,007^{*}$} & \multicolumn{2}{|c|}{$p=0,71$} \\
\hline
\end{tabular}

П р и м е ч а н и е. $*$ - различия достоверны при $p<0,05$.

$\mathrm{N}$ o t e. ${ }^{*}$ - differences are significant at $p<0.05$.

Иммуноморфологическая характеристика экспрессии молекулярных маркеров в группе приобретенной ЭЭД. В группе приобретенных ЭЭД параметры эпителиальной экспрессии люмикана были сравнимы с таковыми в группе контроля с повышением интенсивности экспрессии маркера на фоне применения 1 \%-ного натрия гиалуроната. Одновременно отмечались статистиче- 

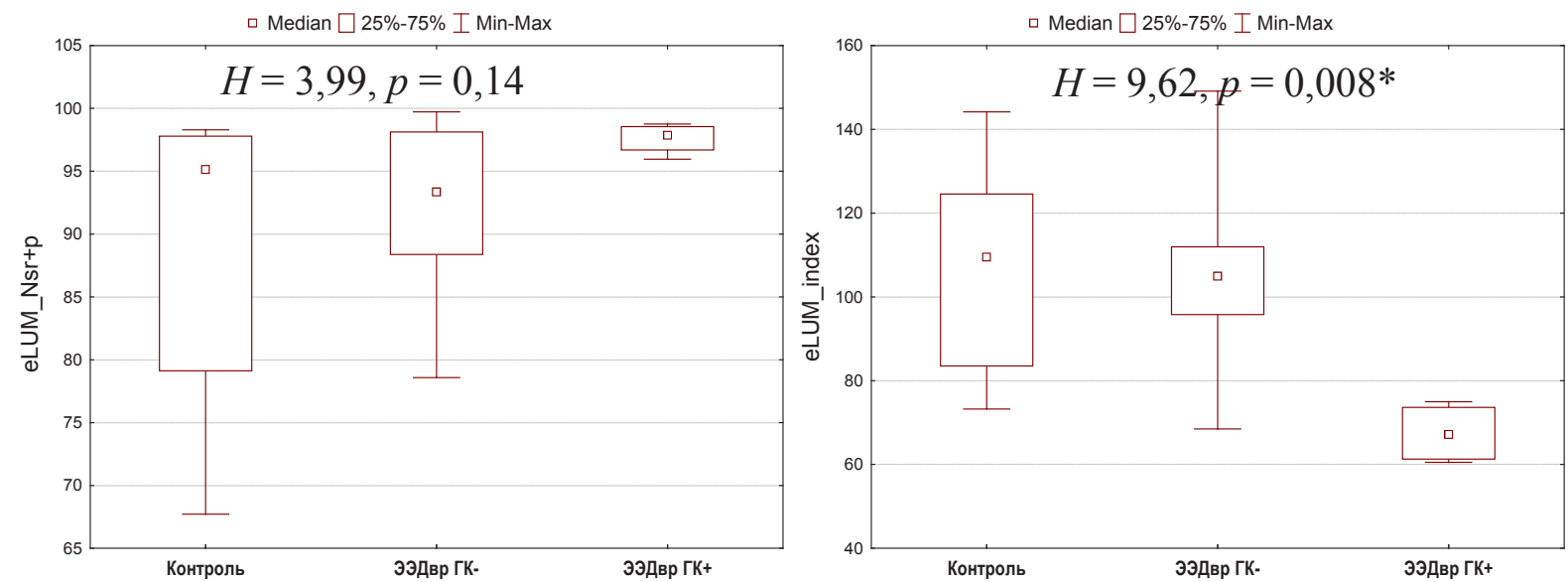

$a$
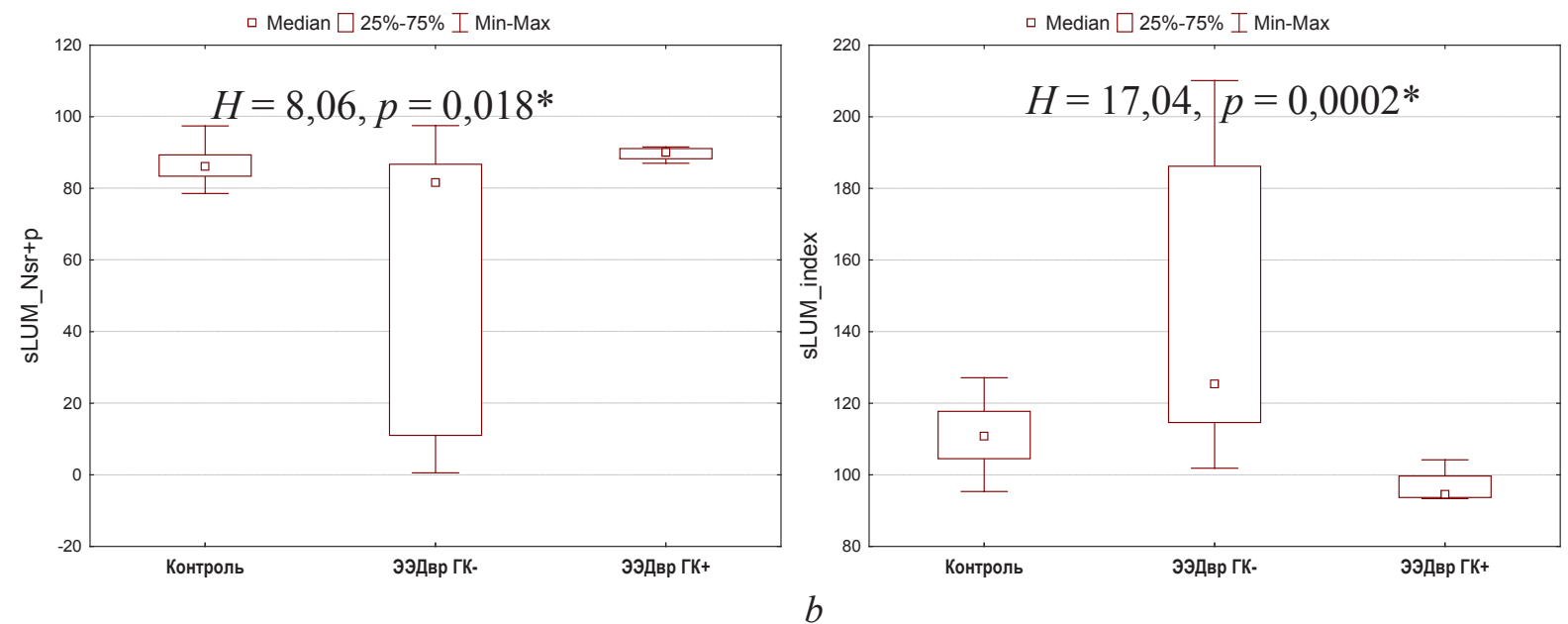

Рис. 3. Индекс интенсивности экспрессии люмикана в эпителии $(a)$ и строме $(b)$ эксплантов роговиц пациентов с врожденной ЭЭД

Fig. 3. Index of the lumican expression intensity in epithelium $(a)$ and stroma $(b)$ of corneal explants of patients with born endothelial-epithelial dystrophy

ски значимо более низкие значения площади выраженной и умеренной стромальной экспрессии маркера в группе приобретенных ЭЭД по сравнению с группой контроля, которые не имели статистически значимых различий вне зависимости от метода лечения (табл. 3 , рис. 4).

Люмикан относится к малым протеогликанам с высоким содержанием лейцина, являющимся основными компонентами экстрацеллюлярного матрикса роговицы. Участвуя в организации коллагеновых фибрилл, они обеспечивают прозрачность роговой оболочки. Люмикан также является необходимым компонентом в процессах миграции эпителиальных клеток и регенерации тканей роговицы. В эксперименте на крысах было отмечено повышение уровня экспрессии люмикана в поздней фазе заживления роговичного повреждения [8]. Примечательно, что в процессе заживления увеличение экспрессии люмикана было отмечено не в строме, а в эпителии роговицы [9].

Характер экспрессии люмикана в группах ХДЗР в исходе кератитов был ассоциирован с тяжестью воспаления в строме, а также выраженностью альтеративных и регенеративных изменений эпителия с наибольшими параметрами интенсивности и площади экспрессии в группе ХДЗР в исходе кератитов на фоне ожоговой болезни и сопоставимыми с группой контроля параметрами экспрессии при формировании бельма.

Применение 1 \%-ного низкомолекулярного натрия гиалуроната имело разнонаправленный эффект. Для группы с ХДЗР в исходе кератитов характерно снижение площади и интенсивности 

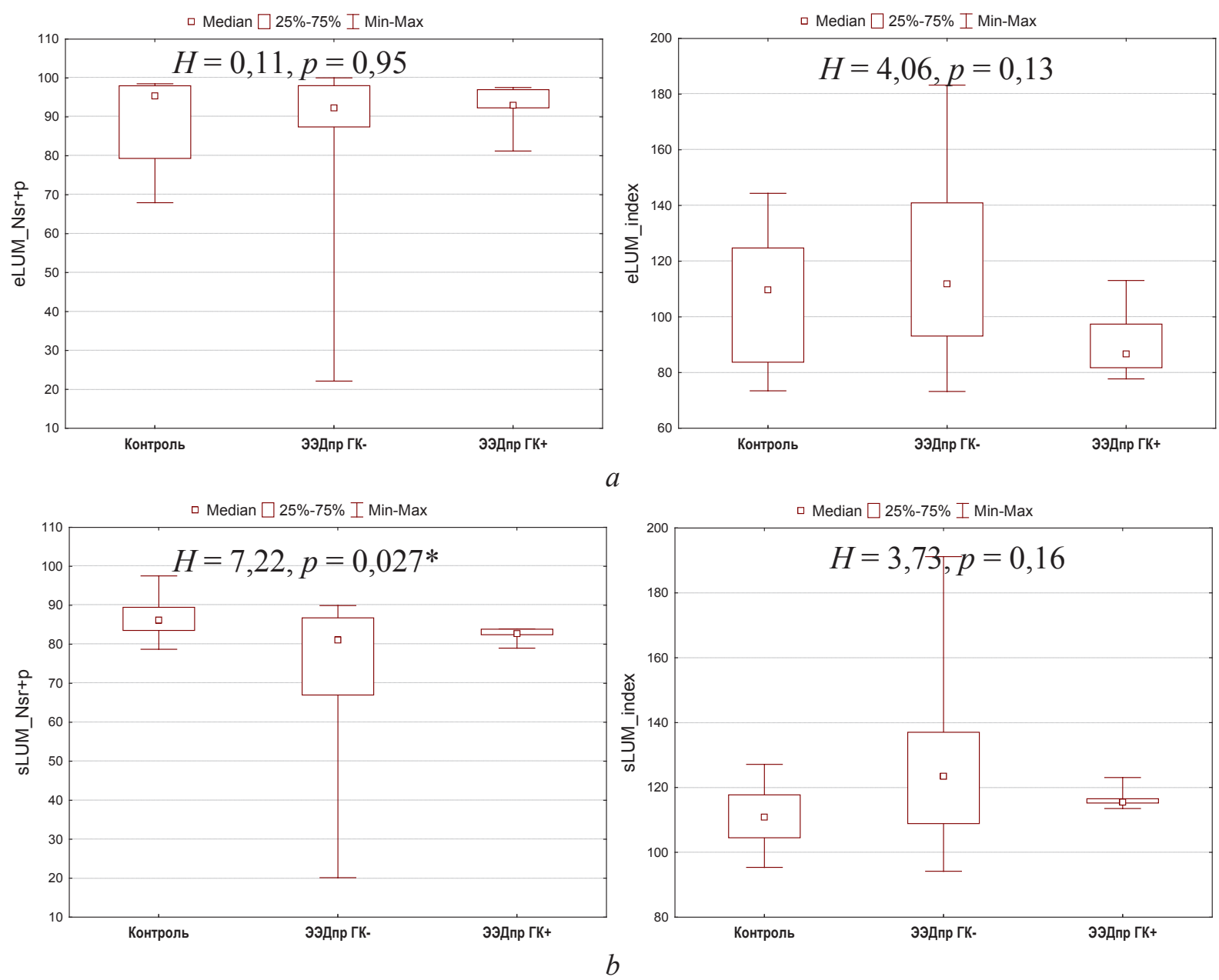

Рис. 4. Индекс интенсивности экспрессии люмикана в эпителии $(a)$ и строме $(b)$ эксплантов роговиц пациентов с приобретенной ЭЭД

Fig. 4. Index of the lumican expression intensity in epithelium $(a)$ and stroma $(b)$ of corneal explants of patients with acquired endothelial-epithelial dystrophy

экспрессии люмикана в эпителии до параметров, сопоставимых с группой контроля с наибольшим эффектом в группе ХДЗР в исходе кератитов на фоне ожоговой болезни. В случае формирования бельма отмечалось повышение интенсивности экспрессии люмикана в эпителии и снижение интенсивности экспрессии маркера в строме по сравнению со стандартной терапией.

В группах ХДЗР при врожденных и приобретенных формах ЭЭД эпителиальная экспрессия люмикана была сопоставима, а стромальная была статистически значимо ниже таковой в группе контроля. Применение 1 \%-ного низкомолекулярного натрия гиалуроната в обеих группах оказывало одинаковый эффект, заключающийся в повышении эпителиальной и стромальной экспрессии люмикана до параметров, как правило, не превышающих таковые группы контроля.

Последние исследования показывают, что малые протеогликаны не только выполняют механическую функцию, но и участвуют во множестве сигнальных путей и таким образом напрямую влияют на процессы регенерации [10].

Повышение экспрессии люмикана в процессе прогрессирования альтеративных изменений, воспаления и заживления способствует миграции и адгезии эпителиальных клеток, привлечению нейтрофилов и макрофагов, пролиферации и своевременному апоптозу стромальных кератоцитов. Люмикан, в частности, способен связываться с рецептором TGF- $\beta$, снижая его биодоступность, замедляя тем самым процессы фиброзирования [10]. 
Функции люмикана также могут быть опосредованы взаимодействием с Fas/FasL, TLR4. Биологическую активность проявляют и продукты расщепления люмикана матриксными металлопротеазами [11].

Ранее дисперсионный анализ экспрессии TGF $\beta 1$ в зависимости от нозологических форм ЭЭД выявил значимо большие показатели экспрессии TGF $\beta 1$ в строме по сравнению с группой контроля во всех исследуемых группах врожденных и приобретенных форм ЭЭД, в том числе формированием амилоидоза на основе TGF $\beta 1$ в двух случаях в группе решетчатых дистрофий. Анализ характера экспрессии TGF $\beta 1$ в ткани роговиц на фоне применения препаратов ГК выявил значимое снижение показателя позитивности стромальной экспрессии в группе приобретенных ЭЭД [2].

Заключение. Применение 1 \%-ного натрия гиалуроната в лечении хронических дистрофических заболеваний роговицы имеет разнонаправленный эффект в зависимости от нозологии и стадии заболеваний данной группы.

Согласно полученным нами результатам показан наиболее явный эффект нового метода лечения в группе ХДЗР в исходе кератитов на фоне ожоговой болезни, характеризующихся выраженными альтеративными, воспалительными и регенеративными изменениями с изначально высокими параметрами экспрессии люмикана, который заключался в более выраженном снижении как эпителиальной, так и стромальной экспрессии маркера до значений контрольной группы по сравнению со стандартным протоколом терапии.

В группах пациентов со сформированными бельмами и ЭЭД наряду с тенденцией к снижению интенсивности стромальной экспрессии, отмечалось некоторое повышение интенсивности эпителиальной экспрессии люмикана при применении нового метода лечения, что свидетельствует об активации процессов регенерации и коррелирует с клиническими признаками улучшения состояния и повышения прозрачности роговицы.

Выявленные закономерности экспрессии люмикана свидетельствуют о его участии как в процессах воспаления и альтерации роговицы, так и регенеративных изменениях. Причем отмеченное повышение эпителиальной экспрессии люмикана на фоне выраженной альтерации сопровождается постепенным ее снижением по мере завершения регенерации. Изучение стромальной экспрессии люмикана показало, что важным фактором является его нормальное содержание в строме роговицы, поскольку как резкое повышение, так и низкие параметры экспрессии сопровождаются снижением прозрачности роговицы.

Использование же нового метода лечения показало его эффективность как в улучшении регенеративных возможностей эпителия роговицы, так и повышении ее прозрачности, подтверждаемой клиническими методами.

\section{Список использованных источников}

1. Особенности экспрессии биомолекулярных маркеров в оценке эффективности лечения дистрофических заболеваний роговицы на фоне глаукомы [Электронный ресурс] / Г. Р. Семак [и др.] // Достижения медицинской науки Беларуси-2019. - Режим доступа: http://med.by/dmn/book.php?book=19-14_10. - Дата доступа 09.03.2020.

2. Особенности экспрессии биомолекулярных маркеров (CD44, MMP9, TGF 1 ) в оценке эффективности лечения эндотелиально-эпителиальной дистрофии роговицы / Г. Р. Семак [и др.] // Вес. Нац. акад. навук Беларусі. Сер. мед. навук. - 2019. - Т. 16, № 4. - С. 477-487. https://doi.org/10.29235/1814-6023-2019-16-4-477-487

3. Degradation of high-molar-mass hyaluronan and characterization of fragments / L. Soltés [et al.] // Biomacromolecules. 2007. - Vol. 8, N 9. - P. 2697-2705. https://doi.org/10.1021/bm070309b

4. Depolymerisation products of hyaluronic acid after exposure to oxygen-derived free radicals / J. D. McNeil [et al.] // Ann. Rheum. Dis. - 1985. - Vol. 44, N 11. - P. 780-789. https://doi.org/10.1136/ard.44.11.780

5. Karbownik, M. S. Hyaluronan: towards novel anti-cancer therapeutics / M. S. Karbownik, J. Z. Nowak // Pharmacol. Rep. - 2013. - Vol. 65, N 5. - P. 1056-1074. https://doi.org/10.1016/s1734-1140(13)71465-8

6. Effect of oxygen-derived reactive species on cartilage proteoglycan-hyaluronate aggregates / E. J. Bates [et al.] // Biochem. Int. - 1984. - Vol. 8. - P. 629-637.

7. The role of lumican in ocular disease / S. Amjadi [et al.] // ISRN Ophthalmol. - 2013. - Vol. 2013. - Art. 632302. https://doi.org/10.1155/2013/632302

8. A Proteomic Approach for Understanding the Mechanisms of Delayed Corneal Wound Healing in Diabetic Keratopathy Using Diabetic Model Rat / T. Yamamoto [et al.] // Int. J. Mol. Sci. - 2018. - Vol. 19, N 11. - P. 3635. https://doi.org/10.3390/ ijms19113635 
9. Dynamic changes of the extracellular matrix during corneal wound healing / E. Lorenzo-Martín [et al.] // Experimental Eye Research. - 2019. - Vol. 186. - Art. 107704. https://doi.org/10.1016/j.exer.2019.107704

10. Frikeche, J. Small leucine-rich repeat proteoglycans in corneal inflammation and wound healing / J. Frikeche, G. Maiti, S. Chakravarti // Exp. Eye Res. - 2016. - Vol. 151. - P. 142-149. https://doi.org/10.1016/j.exer.2016.08.015

11. Distribution and Function of Glycosaminoglycans and Proteoglycans in the Development, Homeostasis and Pathology of the Ocular Surface / S. Puri [et al.] // Front. Cell Dev. Biol. - 2020. - Vol. 8. - Art. 731. https://doi.org/10.3389/ fcell.2020.00731

\section{References}

1. Semak G., Zakharava V., Kletsky S., Liatkouslaya T., Zherka I. Features of the biomolecular markers expression in assessing the effectiveness of the corneal degenerative diseases with the background of glaucoma treatment. Achievements of the medical science of Belarus-2019. Available at: http://med.by/dmn/book.php?book=19-14_10 (accessed 9 March 2020) (in Russian).

2. Semak G. R., Zakharova V. A., Kletsky S. K., Letkovskaya T. A., Zherko I. Yu. Features of the expression of biomolecular markers (CD44, MMP9, TGF 31 ) in assessing the effectiveness of treatment of endothelial-epithelial corneal dystrophy. Vestsi Natsyyanal'nai akademii navuk Belarusi. Seriya meditsinskikh navuk = Proceedings of the National Academy of Sciences of Belarus. Medical series, 2019, vol. 16, no. 4, pp. 477-487 (in Russian). https://doi.org/10.29235/1814-6023-201916-4-477-487

3. Soltés L., Kogan G., Stankovska M., Mendichi R., Rychlý J., Schiller J., Gemeiner P. Degradation of high-molar-mass hyaluronan and characterization of fragments. Biomacromolecules, 2007, vol. 8, no. 9, pp. 2697-2705. https://oi.org/10.1021/ bm070309b

4. McNeil J. D., Wiebkin O. W., Betts W. H., Cleland L. G. Depolymerisation products of hyaluronic acid after exposure to oxygen-derived free radicals. Annals of the Rheumatic Diseases, 1985, vol. 44, no. 11, pp. 780-789. https://oi.org/10.1136/ ard.44.11.780

5. Karbownik M. S., Nowak J. Z. Hyaluronan: towards novel anti-cancer therapeutics. Pharmacological Reports, 2013, vol. 65 , no. 5, pp. 1056-1074. https://doi.org/10.1016/s1734-1140(13)71465-8

6. Bates E. J., Harper G. S., Lowther D. A., Preston B. N. Effect of oxygen-derived reactive species on cartilage proteoglycan-hyaluronate aggregates. Biochemistry International, 1984, vol. 8, pp. 629-637.

7. Amjadi S., Mai K., McCluskey P., Wakefield D. The role of lumican in ocular disease. ISRN Ophthalmology, 2013, vol. 2013, art. 632302. https://doi.org/10.1155/2013/632302

8. Yamamoto T., Otake H., Hiramatsu N., Yamamoto N., Taga A., Nagai N. A Proteomic Approach for Understanding the Mechanisms of Delayed Corneal Wound Healing in Diabetic Keratopathy Using Diabetic Model Rat. International Journal of Molecular Sciences, 2018, vol. 19, no. 11, pp. 3635. https://doi.org/10.3390/ijms19113635

9. Lorenzo-Martín E., Gallego-Muñoz P., Mar S., Fernández I., Cidad P., Martínez-García M. C. Dynamic changes of the extracellular matrix during corneal wound healing. Experimental Eye Research, 2019, vol. 186, art. 107704. https://doi. org/10.1016/j.exer.2019.107704

10. Frikeche J., Maiti G., Chakravarti S. Small leucine-rich repeat proteoglycans in corneal inflammation and wound healing. Experimental Eye Research, 2016, vol. 151, pp. 142-149. https://doi.org/10.1016/j.exer.2016.08.015

11. Puri S., Coulson-Thomas Y. M., Gesteira T. F., Coulson-Thomas V. J. Distribution and Function of Glycosaminoglycans and Proteoglycans in the Development, Homeostasis and Pathology of the Ocular Surface. Frontiers in Cell and Developmental Biology, 2020, vol. 8, art. 731. https://doi.org/10.3389/fcell.2020.00731

\section{Информация об авторах}

Семак Галина Романовна - канд. мед. наук, доцент. Белорусский государственный медицинский университет (пр. Дзержинского, 83, 220116, Минск, Республика Беларусь). E-mail: semakgalina@mail.ru.

Захарова Виктория Алексеевна - канд. мед. наук, доцент. Белорусский государственный медицинский университет (пр. Дзержинского, 83, 220116, Минск, Республика Беларусь). E-mail: zakharava.vikt@gmail.com.

Жерко Ирина Юрьевна - врач-офтальмолог. РНПЦ онкологии и медицинской радиологии им. Н. Н. Александрова (Лесной, 223040, Минский район, Минская обл., Республика Беларусь). E-mail: zherko.irina@mail.ru.

Юдин Павел Юрьевич - врач-офтальмолог. 3-я городская клиническая больница им. Е. В. Клумова (ул. Ленина, 30, 220030, Минск, Республика Беларусь). E-mail: yudin2007@icloud.com.

\section{Information about the authors}

Semak Galina R. - Ph. D. (Medicine), Associate professor. Belarusian State Medical University (83, Dzerzhinsky Ave., 220116, Minsk, Republic of Belarus).E-mail:semakgalina@, mail.ru.

Zakharava Viktoryia A. - Ph. D. (Medicine), Associate professor. Belarusian State Medical University (83, Dzerzhinsky Ave., 220116, Minsk, Republic of Belarus). E-mail: zakharava.vikt@gmail.com.

Zherka Iryna Yu. - Ophthalmologist. N. N. Alexandrov National Cancer Centre of Belarus (Lesnoy, 223040, Minsk District, Minsk Region, Republic of Belarus). E-mail: zherko.irina@mail.ru.

Yudin Pavel Yu. - Ophthalmologist. 3rd City Clinical Hospital named after E. V. Klumov (30, Lenin Str., 220030, Minsk, Republic of Belarus). E-mail: yudin2007@icloud. com. 